\title{
COUETTE-TYPE MHD FLOW WITH SUCTION AND INJECTION UNDER CONSTANT PRESSURE GRADIENT
}

\author{
D.R.Kuiry ${ }^{1}$, Surya Bahadur ${ }^{2}$ \\ ${ }^{1}$ Associate Professor, P.G. Department of Mathematics, Kolhan University, Chaibasa Jharkhand, India \\ ${ }^{2}$ Assistant Professor, Department of Mathematics, R.V.S.College of Engineering \& Technology, Jamshedpur, \\ Jharkhand, India
}

\begin{abstract}
The unsteady magnetohydrodynamic Couette-type flow of an electrically conducting, viscous and incompressible fluid bounded by two parallel non- conducting porous plates under the influence of a constant pressure gradient and a transversely applied uniform magnetic field is studied with heat transfer. A uniform suction on the upper plate and an injection on the lower plate are applied perpendicularly to the plates keeping the rates of suction and injection the same. The two plates are maintained at different but constant temperatures. The governing nonlinear partial differential equations are solved by both analytical as well as numerical methods. An exact solution for the velocity of the fluid has been obtained by Laplace transform method. The Crank-Nicholson implicit method is used to obtain the unsteady fluid velocity profile. The transient part of the fluid velocity tends to zero as the time $t$ tends to infinity. The energy equation is solved by the finite difference method .The effect of the magnetic field coupled with suction and injection on the velocity and temperature distributions is examined graphically and discussed in the present work.
\end{abstract}

Keywords: Magnetohydrodynamics, Transverse magnetic field, Suction and injection, Constant pressure gradient, Transient state flow, Crank-Nicholson implicit method, Finite difference method.

\section{INTRODUCTION}

MHD is the study of interaction of conducting fluids with electromagnetic phenomena. The flow of an electrically conducting fluid in the presence of magnetic field is of importance in various areas of technology and engineering. It has wide applications in many devices like magnetohydrodynamic (MHD) power generation, magnetohydrodynamic pumps, generators, accelerators, aerodynamic heating, and petroleum industry and so on.

The great interest and most physical relevance that can be received by such problem of fluid flow with constant pressure gradient are found through the study of Couetteflow between parallel plates for a viscous, incompressible and electrically conducting fluid under the influence of a transversely applied magnetic field.

A lot of research work regarding the flow between two parallel porous plates has received the attention under different conditions and situations.[2,3,4,6,7,8,9,13,14,16] either in the form of research paper or in the form of book on porous media.

In the present work, we focus on the unsteady viscous, incompressible, electrically conducting fluid flow between the two parallel porous non-conducting flat plates in the presence of constant uniform transverse magnetic field and under constant pressure gradient yielding the solution to be of the form of a sum of steady- state and transient -state fluid flow.
Further it studies to find the solution for steady-state temperature distribution at various wall temperatures equalizing the rate of injection at the lower plate and the rate of suction at the upper plate.

\section{FORMULATION OF THE PROBLEM}

Let us consider a non-steady two dimensional viscous incompressible Couette- type flow under constant pressure gradient between two parallel porous plates and nonconducting flat plates and assume that a constant, uniformly distributed suction or injection $v_{w}$ is applied to the fixed plate. Let the upper plate move with a constant velocity $\mathrm{U}_{0}$ at a fixed distance $d$ from the fixed plate. A uniform constant transverse magnetic field $\vec{H}_{0}$ is applied perpendicularly to the fixed surface. Let the lower plate is at rest be with constant temperature $\mathrm{T}_{0}$ and the upper plate be with constant temperature $T_{1}$.

The Reynolds number is assumed to be small so that the induced magnetic field due to the flow is negligible and the velocity components $(\mathrm{u}, \mathrm{v})$ are both functions of $\mathrm{y}$ and time $\mathrm{t}$ where the temperature $\mathrm{T}$ is a function of $\mathrm{y}$ only, the simplified differential equations of motion [11-12], the equation of continuity, and the equation of energy [15] governing the fluid flow are respectively given in the manner;

$\frac{\partial u}{\partial t}+v \frac{\partial u}{\partial y}=-\left(\frac{1}{\rho} \frac{\partial p}{\partial x}\right)-\frac{\mu^{2} H_{0}^{2} \sigma}{\rho} u+v \frac{\partial^{2} u}{\partial y^{2}}$ 


$$
\begin{aligned}
& \frac{\partial v}{\partial t}+v \frac{\partial v}{\partial y}=-\left(\frac{1}{\rho} \frac{\partial p}{\partial x}\right)+v \frac{\partial^{2} v}{\partial y^{2}} \\
& \frac{\partial v}{\partial y}=0
\end{aligned}
$$

and

$\rho C_{p} v \frac{\partial T}{\partial y}=k \frac{\partial^{2} T}{\partial y^{2}}+\mu \bar{\Phi}$

where

$\bar{\Phi}=2\left(\frac{\partial v}{\partial y}\right)^{2}+\left(\frac{\partial u}{\partial y}\right)^{2}-\frac{2}{3}\left(\frac{\partial v}{\partial y}\right)^{2}$

is known as the dissipation function and $\rho, \mu, \nu, p$ and $\sigma$ are respectively the density, permeability, kinematic viscosity, pressure and electrical conductivity of the fluid. $C_{p}$ and k are the specific heat due to pressure and the thermal conductivity respectively.

The initial and boundary conditions are:

$\mathrm{u}(\mathrm{y}, 0)=0,0 \leq \mathrm{y} \leq d$,

$\mathrm{u}=0(\mathrm{t}>0) ; v=$ const. $=v_{w}(\mathrm{t} \geq 0), \mathrm{T}=\mathbb{T}_{\mathbb{Q}}$ at $\mathrm{y}=0$,

and

$\mathrm{u}=U_{0}(\mathrm{t}>0) ; \mathrm{T}=T_{1}$ at $\mathrm{y}=d$

The equation (3) indicates $\mathrm{v}=v_{w}$ at $\mathrm{y}=0$ resulting

$\mathrm{v}=v_{w}$ everywhere and the equation (2) clears that $\frac{\partial p}{\partial y}=0$ implying that $\mathrm{p}$ is a function of $\mathrm{x}$ only. It is also obvious from the equation (1) that the term $\frac{\partial p}{\partial x}$ must be a constant because of the remaining terms in it are all independent of $\mathrm{x}$ and consequently the equation(1) and (4) reduce in the following manner;

$\frac{\partial u}{\partial t}+v_{w} \frac{\partial u}{\partial y}=-\left(\frac{1}{\rho} \frac{\partial p}{\partial x}\right)-\frac{\mu^{2} H_{0}^{2} \sigma}{\rho} u+v \frac{\partial^{2} u}{\partial y^{2}}$

and

$\rho C_{p} v_{w} \frac{\partial T}{\partial y}=k \frac{\partial^{2} T}{\partial y^{2}}+\mu\left(\frac{\partial u}{\partial y}\right)^{2}$

On substitution of the following non-dimensional variables and parameters:

$$
u^{*}=\frac{u}{U_{*}}, \lambda=\frac{v_{w}}{v} d
$$

where

$$
\begin{gathered}
\lambda>0 \text { : injection, } \lambda<0 \text { : suction } \\
\alpha=\frac{x}{d} ; \beta=\frac{d}{h} ; p^{*}=\frac{p d}{\mu U_{0}} ; K=-\frac{d p^{*}}{d \alpha} ;
\end{gathered}
$$

$$
\begin{aligned}
M^{2}=\frac{\mu^{2} H_{0}^{2} d^{2} \sigma}{\rho v} ; \quad E_{c} & =\frac{U_{0}^{2}}{C_{p}\left(T_{1}-T_{0}\right)} ; \\
P_{r} & =\frac{\mu C_{p}}{k} ; T^{*}=\frac{T-T_{0}}{T_{1}-T_{0}}
\end{aligned}
$$

into the equations (6) and (7) and then omitting the stars for convenience, these equations can be replaced by the following manner;

$\frac{d^{2} u}{d \beta^{2}}-\lambda \frac{d u}{d \beta}-\left(\frac{d^{2}}{v}\right)\left(\frac{d u}{d \beta}\right)-M^{2} u+K=0$

and

$\frac{d^{2} T}{d \beta^{2}}-P_{r} \lambda \frac{d T}{d \beta}+P_{r} E_{c}\left(\frac{d u}{d \beta}\right)^{2}=0$

subject to the initial and boundary conditions:

$$
u(\beta, 0)=0,0 \leq \beta \leq 1
$$

$u=0,(t>0), T=0$ at $\beta=0$

and

$$
u=1,(t>0) ; T=1 \text { at } \beta=1 \text {, }
$$

where $\lambda, K, M, P_{r}$ and $E_{c}$ denote respectively the suction parameter, pressure gradient, Hartmann number, Prandtl number and Eckert number.

\section{SOLUTION OF THE PROBLEM}

For unsteady viscous, incompressible Couette -Type flow under a constant pressure gradient and a constant uniform transverse magnetic field when the lower plate is stationary and the upper plate moves with a uniform velocity $\mathrm{U}_{0}$, it needs to solve the equation(8) subject to the initial and boundary conditions:

$u(\beta, 0)=0,0 \leq \beta \leq 1$

$$
u=0 \quad(t>0) \text { at } \beta=0
$$

and

$u=1(t>0)$ at $\beta=1$

Employing the Laplace transform [13] defined by

$$
\overline{\mathrm{u}}=\int_{0}^{\propto} e^{-s t} u(\beta, t) d t
$$

into the equation (8) and using (11), it yields in the form:

$\frac{d^{2} \bar{u}}{d \beta^{2}}-\lambda \frac{d \bar{u}}{d \beta}-\left(\frac{d^{2}}{v}\right) s \bar{u}-M^{2} \bar{u}+\frac{K}{s}=0$

with the initial and boundary conditions

$$
\bar{u}(0, s)=0 \text { at } \beta=0
$$


and

$$
\bar{u}(1, s)=\frac{1}{s} \text { at } \beta=1
$$

Consequently the solution to the equation (13) subject to the conditions (14) is given in the form:

$\bar{u}=\frac{1}{s}\left(\frac{e^{\beta m_{1}}-e^{\beta m_{2}}}{e^{m_{1}}-e^{m_{2}}}\right)$

$+\frac{K}{s\left(\frac{s d^{2}}{v}+M^{2}\right)}\left[\frac{e^{\beta m_{2}}\left(1-e^{m_{1}}\right)-e^{\beta m_{1}}\left(e^{m_{2}}-1\right)}{e^{m_{1}}-e^{m_{2}}}+1\right]$

where $\mathrm{m}_{1}$ and $m_{2}$ are the roots of the auxiliary equation (13).

Where

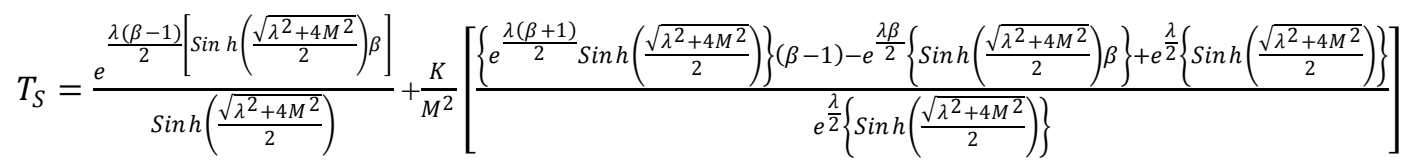

and

$$
\begin{aligned}
T_{r} \text { is equal to } \sum_{n=0}^{n=\infty} & {\left[\frac{(8 n \pi) \exp \cdot\left\{\frac{-v t}{4 d^{2}}\left(4 n^{2} \pi^{2}+\lambda^{2}+4 M^{2}\right)\right\}}{4 n^{2} \pi^{2}+\lambda^{2}+4 M^{2}}\left\{\frac{\sin (n \pi \beta)}{\sin (n \pi)}\right\} e^{\left.\left\{\frac{\lambda(\beta-1)}{2}\right\}\right]}\right.} \\
+ & {\left[\left(\frac{32 n \pi K}{e^{\frac{\lambda}{2}}}\right)\left\{\frac{\exp \cdot\left\{\frac{-v t}{4 d^{2}}\left(4 n^{2} \pi^{2}+\lambda^{2}+4 M^{2}\right)\right\}}{\left(4 n^{2} \pi^{2}+\lambda^{2}\right)\left(4 n^{2} \pi^{2}+\lambda^{2}+4 M^{2}\right)}\right\}\right] e^{\frac{\lambda \beta}{2}}\left[\frac{\sin (n \pi \beta)-e^{\frac{\lambda}{2}} \sin \{n \pi(\beta-1)\}}{\cos n \pi}\right] }
\end{aligned}
$$

$T_{S}$ is the steady state fluid flow and $T_{r}$ is the transient state fluid flow.

Inverting the equation (15) by the inversion theorem [13-14] defined by

$$
u=\frac{1}{2 \pi i} \lim _{\theta \rightarrow \infty} \int_{\eta-i \theta}^{\eta+i \theta} e^{s t} \bar{u} d s
$$

it yields the unsteady state fluid flow in the manner below:

$u=T_{s}+T_{r}$
Now the energy equation (9) with the conditions;

$$
\mathrm{T}=0 \text { at } \beta=0
$$

and

$$
\mathrm{T}=1 \text { at } \beta=1
$$

is solved by finite difference method [1] for the steady state temperature distribution between the two parallel porous flat plates of which the lower plate having constant temperature $T_{0}$ is at rest while the upper plate having the constant temperature $T_{1}$ is moving with uniform velocity $U_{0}$. The equation (8) has been solved by two different methods .The Laplace Transform method has been applied to obtain the solution in terms of the sum of two expressions (16) out of which the second term $T_{r}$ vanishes as the time $\mathrm{t} \rightarrow \infty$. In this case the solution for steady state flow is obtained .Again the equation(8) is solved numerically by employing the Crank-Nicholson implicit method[10] .The numerical data so obtained is used to show the velocity profile in the unsteady case through the figure -1 . The data given in the table -1 for fluid flow velocity $u$ and the ordinate $\beta$ at the two successive time levels with step sizes $\Delta t=0.5,1,1.5$ and 2 for the time and the space sizes $\Delta \beta=0.2$ and accordingly the table is given after computing for various values of $\beta=0$ $0.2,0.4,0.6,0.8$ and 1 for each case of values of $\Delta t$. The application of this method provides the pivotal values of the velocity $u$ at $\beta=0,0.2,0.4,0.6,0.8$, and 1 .This data is used to obtain the velocity profiles for the unsteady case. The velocity increases with the increase of time.

The energy equation (9) subject to the conditions (17) has been solved by using the finite difference method [10] to get the temperature distributions between the two parallel plates.

The graphs of the temperatures profiles for conduction and convection have been depicted with respect to the dimensionless perpendicular distance $\beta$ from the stationary plate as shown in the figure-2 through5.Again the temperature profiles with respect to the dimensionless perpendicular distance $\beta$ for different values of $\mathrm{K}=0,-1,-3$,5 have been displayed graphically in the figure -6 .

\section{CONCLUSION}

The fluid flow profiles are shown in the figure -1 . It is observed that for unsteady state case of fluid flow, the velocity increases for the increasing $\Delta t$ and for fixed values of Hartmann number $M$, pressure gradient $\mathrm{K}$ and suction parameter $\lambda$.

From the figure-1, it is obvious that as $t \rightarrow \infty$ then $T_{r} \rightarrow 0$ and on account of the viscous diffusion of momentum, the effect of the upper plate is felt more and more by the interior fluid and as a result the steady state flow velocity is attained i.e. $u=T_{s}$ 
Further if the values of $v$ and $\mathrm{M}$ increase, from the equation (16) it is observed that the transient state fluid flow $T_{r}$ decays rapidly. Again time taken to reach the steady state $T_{S}$ depends upon the suction or injection parameter $\lambda$ which is clear from the figure -1 .

The conduction profiles are shown through the figure- 2 to 3.it makes clear that the effect of magnetic field $M$ is prominent in the case of conduction. Increasing $M$, we observe that the flow of heat through conduction decreases and increasing $\mathrm{M}$ retards the flow of heat.
The convection profiles are exhibited through the figures-4 and 5.It is observed that the heat flow through convection is comparatively higher. Increasing $M$ retards the heat flow in this case also.

The figure- 6 shows that the flow of heat depends upon pressure gradient $\mathrm{K}$ and this heat flow increases rapidly as we go on decreasing the pressure gradient $\mathrm{K}$.

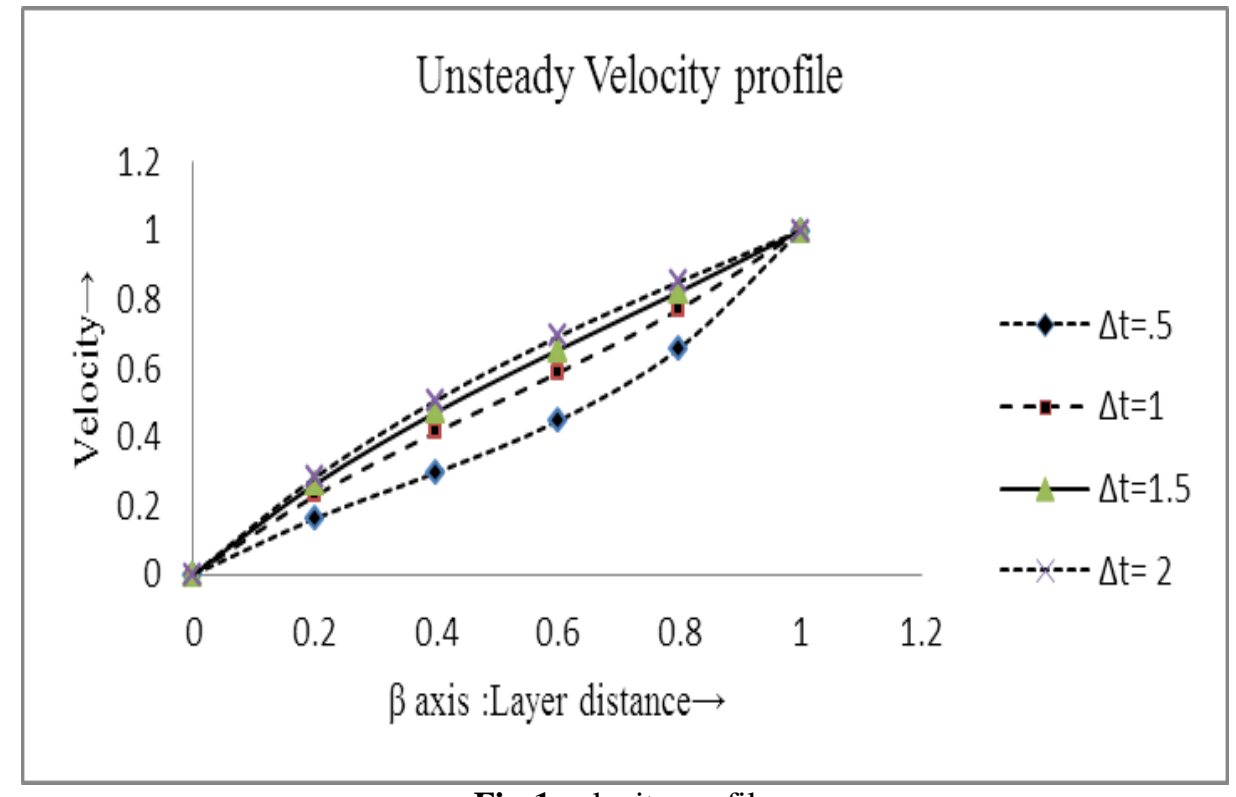

Fig-1 velocity profile

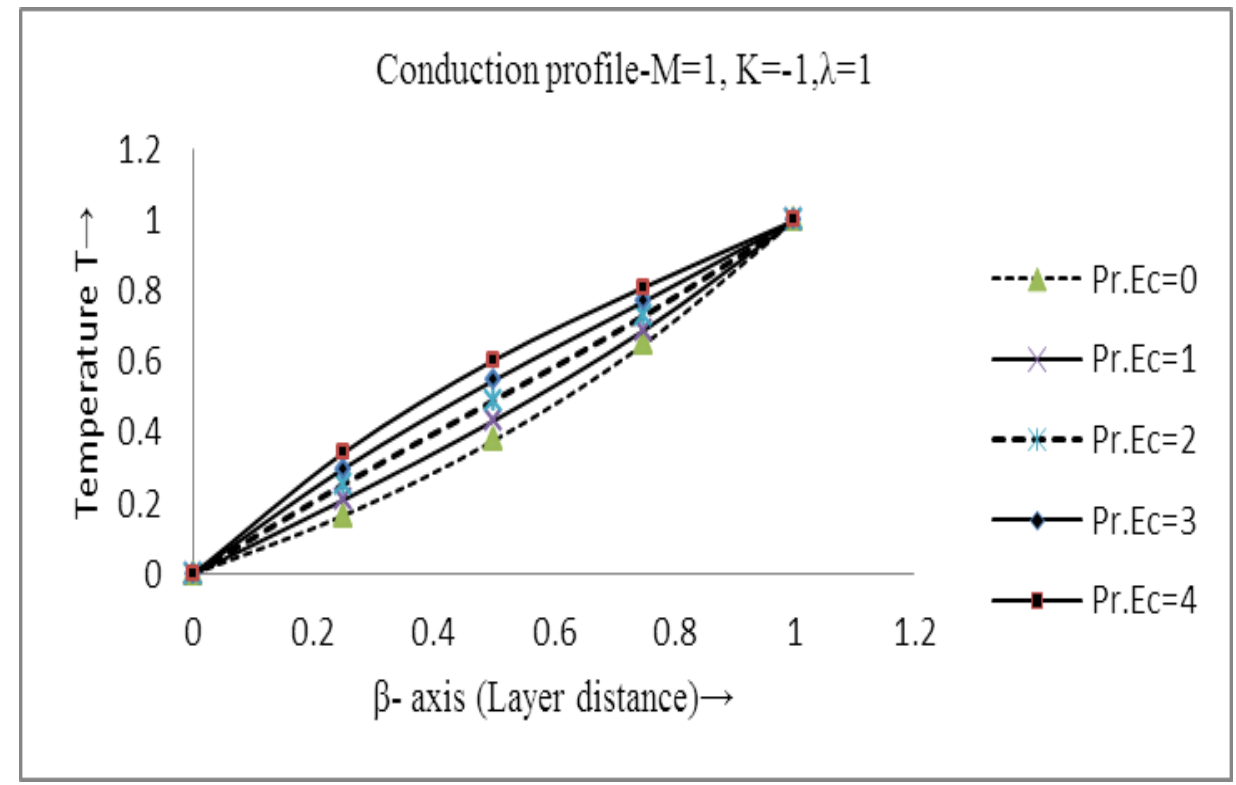

Fig-2: conduction profile for $M=1$ 


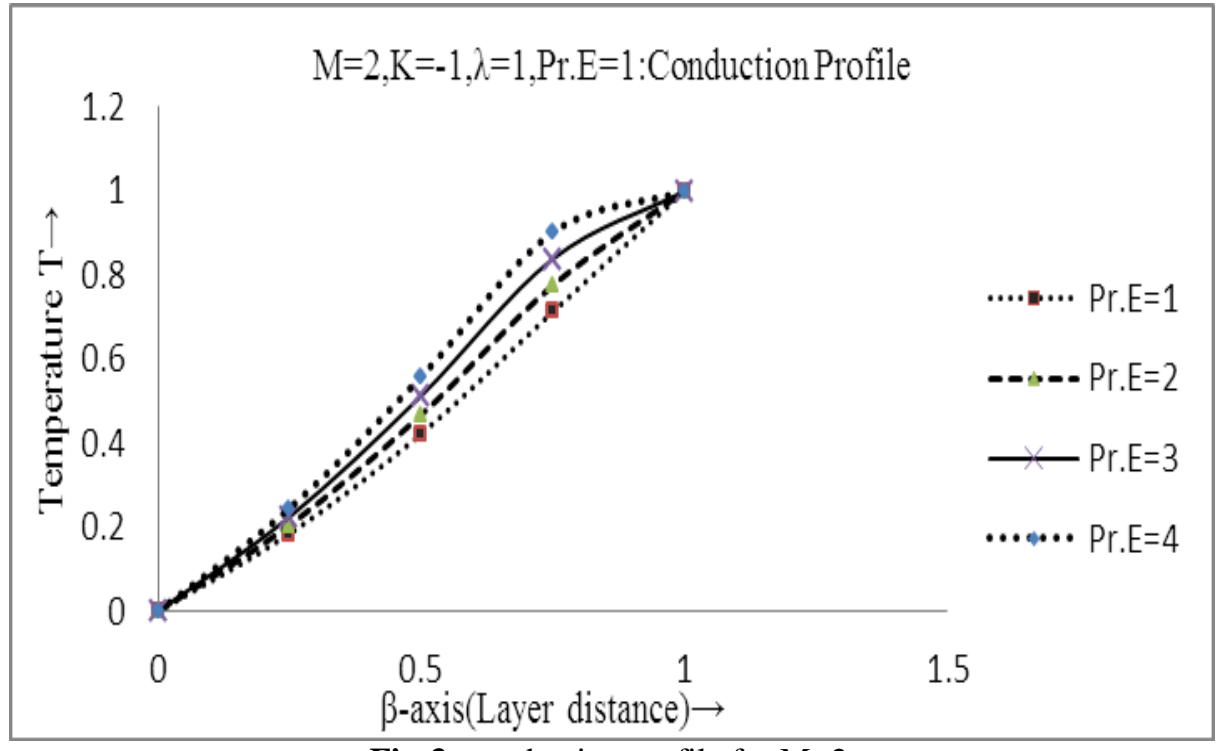

Fig-3: conduction profile for $\mathrm{M}=2$

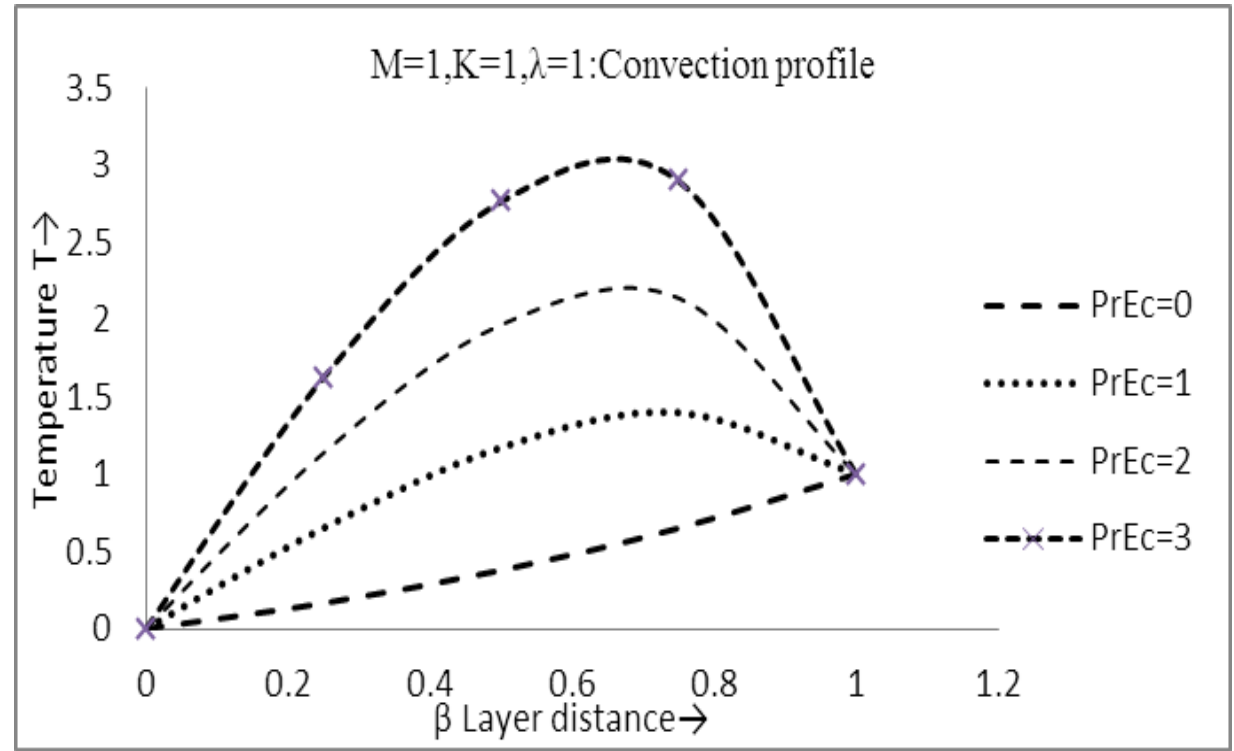

Fig-4: convection profile for $\mathrm{M}=1$

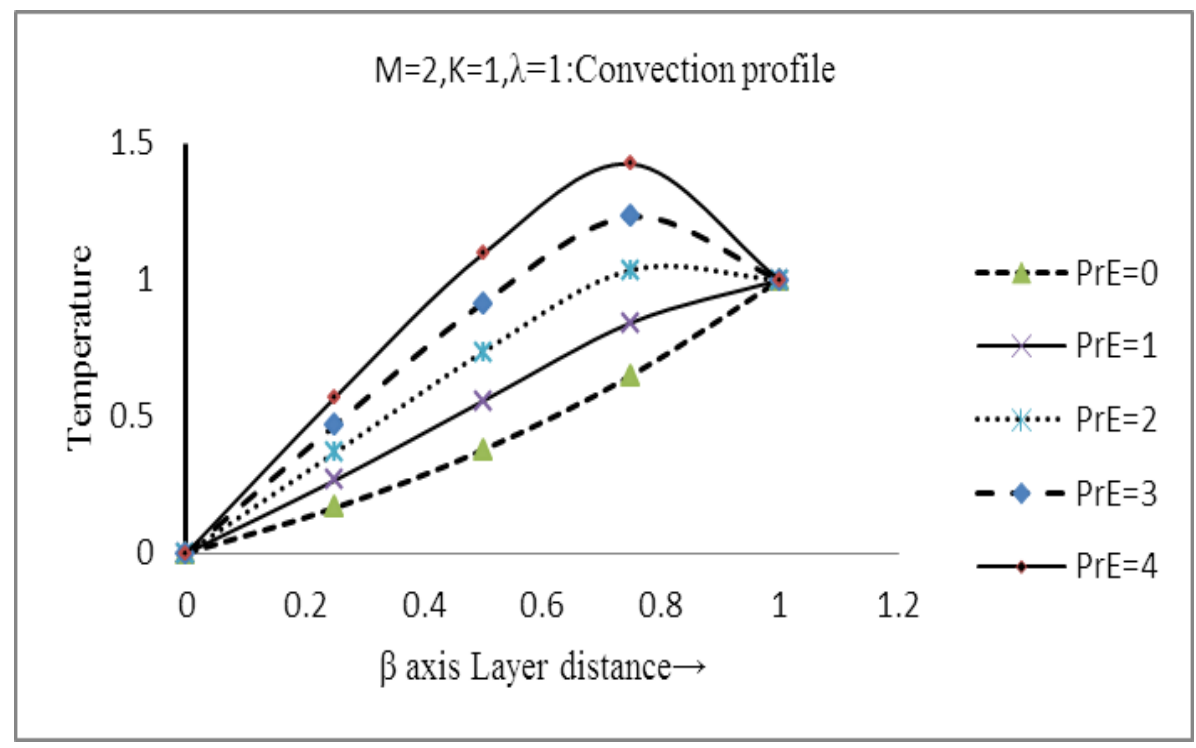

Fig-5: convection profile for $\mathrm{M}=2$ 


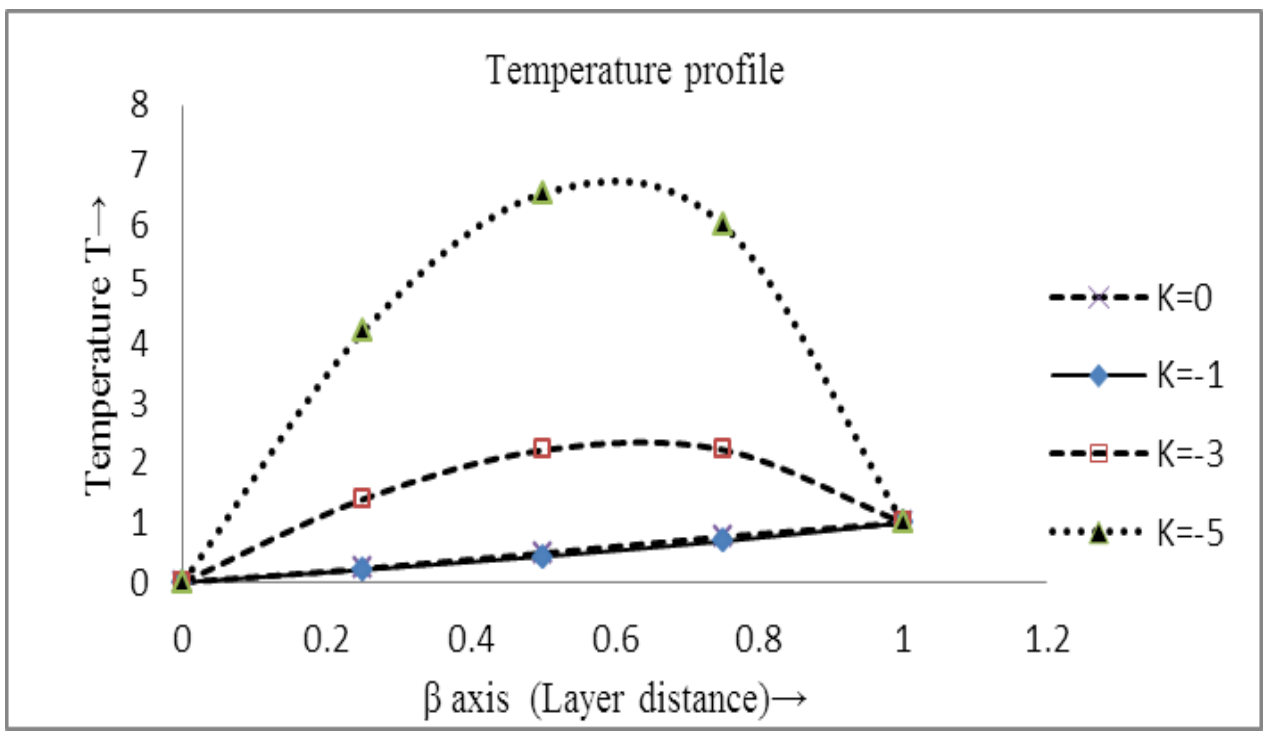

Fig-6: Temperature profile with respect to dimensionless perpendicular distance for different values of $\mathrm{K}$

Table-1 Unsteady velocity profile

\begin{tabular}{|l|l|l|l|l|}
\hline & \multicolumn{1}{|c|}{$\Delta t=0.5$} & $\Delta t=1$ & $\Delta t=1.5$ & $\Delta t=2$ \\
\hline$\beta$ & $\mathrm{u}$ & $\mathrm{u}$ & $\mathrm{u}$ & $\mathrm{u}$ \\
\hline 0 & 0 & 0 & 0 & 0 \\
\hline 0.2 & 0.162335 & 0.228783 & 0.262048 & 0.281905 \\
\hline 0.4 & 0.296617 & 0.414172 & 0.472049 & 0.506362 \\
\hline 0.6 & 0.445817 & 0.585828 & 0.652400 & 0.691328 \\
\hline 0.8 & 0.657679 & 0.771213 & 0.822342 & 0.851600 \\
\hline 1 & 1 & 1 & 1 & 1 \\
\hline
\end{tabular}

Table-2 Conduction profile for $\mathrm{M}=1$

\begin{tabular}{|l|l|l|l|l|l|}
\hline \multicolumn{1}{|c|}{$\beta$} & PrEc=0 & PrEc=1 & PrEc=2 & PrEc=3 & PrEc=4 \\
\hline 0 & 0 & 0 & 0 & 0 & 0 \\
\hline 0.25 & 0.16529 & 0.20938 & 0.25386 & 0.29834 & 0.34282 \\
\hline 0.5 & 0.377541 & 0.433909 & 0.490895 & 0.547881 & 0.60486 \\
\hline 0.75 & 0.650068 & 0.68998 & 0.730441 & 0.770901 & 0.81136 \\
\hline 1 & 1 & 1 & 1 & 1 & 1 \\
\hline
\end{tabular}

Table-3 Conduction profile for $\mathrm{M}=2$

\begin{tabular}{|l|l|l|l|l|}
\hline \multicolumn{1}{|c|}{$\beta$} & PrEc=1 & PrEc=2 & $\operatorname{PrEc}=3$ & $\operatorname{PrEc}=4$ \\
\hline 0 & 0 & 0 & 0 & 0 \\
\hline 0.25 & 0.184991 & 0.205077 & 0.225164 & 0.245249 \\
\hline 0.5 & 0.422334 & 0.467744 & 0.513154 & 0.558563 \\
\hline 0.75 & 0.712669 & 0.775817 & 0.838966 & 0.902114 \\
\hline 1 & 1 & 1 & 1 & 1 \\
\hline
\end{tabular}

Table-4 Convection profile for $\mathrm{M}=1$

\begin{tabular}{|l|l|l|l|l|}
\hline \multicolumn{1}{|c|}{$\beta$} & PrEc=0 & $\operatorname{PrEc}=1$ & $\operatorname{PrEc}=2$ & $\operatorname{PrEc}=3$ \\
\hline 0 & 0 & 0 & 0 & 0 \\
\hline 0.25 & 0.165297 & 0.651139 & 1.137364 & 1.623595 \\
\hline 0.5 & 0.377541 & 1.172118 & 1.967313 & 2.762508 \\
\hline 0.75 & 0.650068 & 1.398902 & 2.140285 & 2.897669 \\
\hline 1 & 1 & 1 & 1 & 1 \\
\hline
\end{tabular}


Table-5 Convection profile for $\mathrm{M}=2$

\begin{tabular}{|l|l|l|l|l|l|}
\hline$\beta$ & $\operatorname{PrEc}=0$ & $\operatorname{PrEc}=1$ & $\operatorname{PrEc}=2$ & $\operatorname{PrEc}=3$ & $\operatorname{PrEc}=4$ \\
\hline 0 & 0 & 0 & 0 & 0 & 0 \\
\hline 0.25 & 0.165297 & 0.26578 & 0.366656 & 0.467533 & 0.568408 \\
\hline 0.5 & 0.377541 & 0.556545 & 0.736167 & 0.915789 & 1.09541 \\
\hline 0.75 & 0.650068 & 0.843412 & 1.037305 & 1.231197 & 1.425089 \\
\hline 1 & 1 & 1 & 1 & 1 & 1 \\
\hline
\end{tabular}

Table-6 Temperature profile for different values of pressure gradient $\mathrm{K}$

\begin{tabular}{|l|l|l|l|l|}
\hline & $\mathrm{K}=0$ & $\mathrm{~K}=-1$ & $\mathrm{~K}=-2$ & $\mathrm{~K}=-3$ \\
\hline$\beta$ & $\mathrm{T}$ & $\mathrm{T}$ & $\mathrm{T}$ & $\mathrm{T}$ \\
\hline 0 & 0 & 0 & 0 & 0 \\
\hline 0.25 & 0.226795 & 0.209385 & 1.394652 & 4.206697 \\
\hline 0.5 & 0.487659 & 0.433909 & 2.218013 & 6.524251 \\
\hline 0.75 & 0.764235 & 0.685939 & 2.222412 & 5.996099 \\
\hline 1 & 1 & 1 & 1 & 1 \\
\hline
\end{tabular}

\section{REFERENCES}

[1]. M. Anita, Numerical Method for Scientists and Engineers, Tata Mc-GrawHill., New Delhi (1991).

[2]. H.A. Attia and K.M. Ewis, Unsteady MHD Couette flow with heat transfer of a viscoelastic fluid under exponentially decaying pressure gradient, Tamkang J.Sci \&Engg.vol.13, No.4 pp. 359-364(2010).

[3]. H.A. Attia, Unsteady MHD Couette Flow and Heat Transfer of Dusty Fluid with variable physical properties, Applied Mathematics and Computation, 177, No.1, (2000) ,308- 318

[4]. J. Bear, Dynamics of Fluids in porous media,Dover(1988)

[5]. R.V. Churchill, Modern Operational Mathematics in Engineering, p.157, Mc- Graw-Hill Book Co, Inc, New York (1944).

[6] .D.F Griffiths, and A.R, Mitchell, The Finite Difference Method in Partial Differential Equations, John Wiley, New York (1980).

[7]. D.B. Ingham and I Pop., Transport Phenomena in Porous Media, Pergamon Pren,Oxford (2002).

[8]. D.R. Kuiry, Generalized porous-wall Couette-Type MHD flow, J. Indian Math.Soc, 67, 1-4, 117-121 (2000).

[9]. D.R. Kuiry, On Hartmann -and-neutral Point type MHD flow in a duct, J. Indian Math.Soc, 78, 1-4, 7986(2011)

[10]. T.K. Mahato and D.R. Kuiry, Hydromagnetic flow of a viscous, incompressible fluid over a naturally permeable bed , Indian J.Theor.Phy.,47,No.2,139-148(1999).

[11]. A. R. Mitchell and D.F Griffiths, The Finite Difference Method in Partial Differential Equations, John Wiley, New York (I980).

[12]. H. Schlichhling, Boundary Layer Theory, McGrawHill Book Co., New York (1986).

[13]. J.A. Shercliff, A Text Book of Magnetohydrodynamics ,Mc-GrawHill Book Co., New York (1965).
[14]. V.M. Soundalgekar, Hall and Ion-slip and Effects in MHD Couette Flow with heat transfer, IEEE Transaction on Plasma Science, PS-14, 579 (1986).

[15]. V.M. Soundalgekar and A.G., Uplekar, Hall Effects in MHD Couette Flow with Heat Transfer, IEEE Transactions on plasma science, PS-14, 579(1986)

[16]. R Spigel, Theory and Problems of Laplace Transform, Mc-GrawHill Book Co., New York (1986).

\section{BIOGRAPHIES}

DR. D. R. Kuiry, He was born in a village near Ranchi, Jharkhand. He has completed post-graduation from Burdwan University, Burdwan, West Bengal. He was awarded Ph.D from B.R. Ambedkar Bihar University, Muzaffarpur in $20^{\text {th }}$ June 1990 . His field of research is " Magnetohydrodynamics'. At present he is Head of P.G.Department of Mathematics, Kolhan University, Chaibasa, Jharkhand.

Surya Bahadur, He was born in Jamshedpur, Jharkhand. He has completed M.Sc. from Ranchi University; Jharkhand .He is working as an assistant professor in R.V.S.College of Engineering \& Technology, Edlbera, NH-33 near Jamshedpur. He has 10 years' experience in teaching applied mathematics. He is a research scholar under the supervision of Dr.D.R.Kuiry \& is registered in Kolhan University, Chaibasa, Jharkhand. 